\title{
Histology of ovaries of female rabbits immunized with deglycosylated zona pellucida macromolecules of pigs
}

\author{
G. R. Jones*, A. G. Sacco, M. G. Subramanian, M. Kruger, S. Zhang, \\ E. C. Yurewicz and K. S. Moghissi
}

Wayne State University School of Medicine, Department of Obstetrics and Gynecology, C.S. Mott Center for Human Growth and Development, Detroit, MI 48201, USA

\begin{abstract}
Summary. Female rabbits ( $n=36,6$ per group) were immunized with: (i) solubilized isolated porcine zona pellucida (SIZP), which contains ZP1, $82 \mathrm{kDa}$; ZP3 $\alpha, 55 \mathrm{kDa}$; and $Z \mathrm{P} 3 \beta, 55 \mathrm{kDa}$; (ii) a purified preparation of $Z \mathrm{P} 3 \alpha$ and $Z \mathrm{P} 3 \beta$ (ZP3); (iii) purified endo- $\beta$-galactosidase digested glycoproteins ZP3 $\alpha-(E B G D)$ and (iv) ZP3 $\beta$-(EBGD) (each about $30 \%$ deglycosylated); (v) chemically deglycosylated core proteins $Z P 3 \alpha-$ (DG) and (vi) ZP3 $\beta$-DG (each $>92 \%$ deglycosylated). Rabbits injected with saline $(n=6)$ or Freund's adjuvant $(n=6)$ served as controls. Rabbits were bled weekly to monitor titres. Every six weeks two animals from each group $(n=16)$ were selected for unilateral oophorectomy followed by histological examination. Sections were scored for numbers of primary, secondary and tertiary follicles. Anti-ZP3 titres developed in all treatment groups and correlated with carbohydrate content (peak per cent $\left[{ }^{125} \mathrm{I}\right]$-labelled ZP3 binding by radioimmunoassay: SIZP $71 \cdot 9 \pm 1 \cdot 2, \mathrm{ZP} 370 \cdot 0 \pm 2 \cdot 5$, ZP3 $\alpha$-EBGD $60 \cdot 9 \pm 5 \cdot 3$, ZP3 $\beta$-EBGD $56 \cdot 4 \pm 5 \cdot 0$, ZP3 $\alpha$-DG $56 \cdot 4 \pm 4 \cdot 0$, ZP3 $\beta$-DG $53.5 \pm 4 \cdot 3$ ) (means \pm SEM). Animals immunized with SIZP, ZP3 and ZP3 $3-E B G D$ showed a statistically significant reduction in the number of primary, secondary and tertiary follicles compared with controls $(P<0.01$, MANOVA), whereas animals immunized with ZP3 $\alpha$-EBGD, ZP3 $\alpha$-DG and ZP3 $\beta$-DG did not ( $P>0.05$, MANOvA). These results demonstrate that immunization with purified $Z P 3 \alpha$ macromolecules (ZP3 $\alpha$-EBGD, ZP3 $\alpha$-DG) or ZP3 $\beta$-DG does not produce histopathological changes in ovaries. Such deglycosylated ZP macromolecules represent potential target antigens for immunocontraceptive development.
\end{abstract}

Keywords: zona pellucida; deglycosylation; follicular development; ovarian histology; immunocontraception, rabbit

\section{Introduction}

The zona pellucida is a noncellular layer that surrounds the mammalian oocyte and preimplantation embryo. Numerous investigations among various species have revealed that it is composed of three to four developmentally regulated glycoproteins that serve essential functions during fertilization and early development (Dunbar et al., 1981; Sacco et al., 1981; Hedrick \& Wardrip, 1987; Yurewicz et al., 1987; Wassarman, 1988), such as species-specific attachment and binding of spermatozoa (Hanada \& Chang, 1972; O'Rand, 1988), induction of the acrosome reaction (Bleil \& Wassarman, 1983; Cherr et al., 1986) and the block to polyspermy (Braden et al., 1954).

Biological and immunological studies indicate that the zona is a potent heteroimmunogen: zonae from different species share common antigenic determinants and zona antisera possess contraceptive activity in vitro and in vivo (Sacco, 1981; Dunbar, 1983; Maresh \& Dunbar, 1987;

${ }^{*}$ Correspondence to Dr Gary R. Jones, 4483 Sweet Shrub Court, Concord, CA 94521. 
Henderson et al., 1988). Human and porcine zonae share common antigens (Sacco, 1977; Koyama et al., 1985) and antiserum to porcine zonae demonstrates contraceptive efficacy in humans (Trounson et al., 1980; Henderson et al., 1987a). Consequently, the porcine zona has gained considerable attention as a potential immunocontraceptive target antigen for possible development of a human contraceptive vaccine (Yurewicz et al., 1986; Sacco, 1987; Sacco et al., 1990; Sacco et al., 1991).

Porcine zona-based immunocontraception has been shown to be exceptionally effective in inhibiting fertility in many species. Its mechanism of action has been presumed to be antibody disruption of sperm-egg interaction at the level of the zona. However, recent studies in vivo in several species including primates revealed that immunization with porcine zona material may also inhibit fertility at the level of the ovary by disrupting folliculogenesis (Sacco et al., 1983; Skinner et al., 1984; Mahi-Brown et al., 1985; Henderson et al., 1988; Upadhyay et al., 1989). This method of inhibiting fertility by zona antibodies is obviously not suitable for use in humans. Recent studies of zona-based immunocontraception have therefore concentrated on approaches directed towards obviating disruptive effects on normal ovarian function after immunization with zona material.

One approach is to consider selection of appropriate porcine zona immunogens for immunization. Such immunogen candidates include: (i) an isolated and highly purified glycoprotein family; (ii) a deglycosylated or partially deglycosylated preparation of such a glycoprotein family; (iii) a proteolytic fragment or synthetic peptide from a specific zona glycoprotein; or (iv) a specific genetically engineered zona epitope product. A recent study performed in rabbits using specific partially deglycosylated and deglycosylated porcine zona components as immunogens clearly indicated that high-titred zona antisera could be raised without disturbance of ovarian hormones (Keenan et al., 1991). The aim of the present study was to evaluate, histologically, ovaries from immunized rabbits. Our results revealed that rabbits immunized with some of these deglycosylated zona fractions also showed no disruption of follicular development compared with controls. Coupled with the earlier endocrinological data from this species, it is concluded that immunization with certain porcine zona fractions does not produce adverse effects on the ovary. These data thus encourage continued investigation of such components for immunocontraceptive purposes.

\section{Materials and Methods}

\section{Antigen preparation}

SIZP. Heat-solubilized isolated zonae pellucida (SIZP) were obtained as described by Yurewicz $e t$ al. $(1983,1987)$. Porcine ovaries (in groups of 1000) were homogenized in Tris- $\mathrm{HCl}$ buffer $\left(0.05 \mathrm{~mol} \mathrm{l}^{-1}, \mathrm{pH} \mathrm{8.0)}\right.$ and the released zonae-encased oocytes collected by passage of the homogenate over nylon monofilament screens (TTKO, NJ, USA) of decreasing pore size $(500-100 \mu \mathrm{m})$. Isolated zonae were collected by homogenizing the oocytes in a glass-teflon tissue grinder and passing the material over a $40 \mu \mathrm{m}$ screen to obtain the broken zonae.

Zonae were suspended in $100 \mathrm{ml}$ of $0.02 \mathrm{~mol}$ Tris buffer $1^{-1}, \mathrm{pH} 8.0$ and the suspension washed by stirring for $60 \mathrm{~min}$ using a magnetic stirrer. The washed zonae were recollected on a $40 \mu \mathrm{m}$ screen, suspended in $20 \mathrm{ml}$ of Tris buffer and heat solubilized by incubation in a $73^{\circ} \mathrm{C}$ water bath for $20 \mathrm{~min}$. The solubilized zonae solution was then centrifuged $(27000 \mathrm{~g}$ for $15 \mathrm{~min})$ and the supernatant (SIZP) decanted and stored at $-20^{\circ} \mathrm{C}$.

ZP3. SIZP is composed of three glycoproteins termed ZPI $\left(M_{\mathrm{r}}=82000\right), Z P 3 \alpha\left(M_{\mathrm{r}}=55000\right)$ and ZP3 $\beta$ $\left(M_{\mathrm{r}}=55000\right)$. ZP3 (composed of ZP3 $\alpha$ and ZP3 $\beta$ ) was isolated from SIZP as described by Yurewicz et al. (1987). Briefly, SIZP from 4000 ovaries was pooled and concentrated by ultrafiltration to a 5-7 ml volume using an Amicon PM-30 membrane. Solid sodium dodecyl sulfate (SDS) was added ( $3 \mathrm{mg} \mathrm{SDS} \mathrm{mg}^{-1}$ protein) and the solution heated to $60^{\circ} \mathrm{C}$ for $30 \mathrm{~min}$. ZP3 was isolated by sequential column chromatography first on Sephacryl S-400 resin (coupled columns, $1.6 \times 95 \mathrm{~cm}$ ) and second on hydroxyapatite resin (column size $=1.6 \times 15 \mathrm{~cm}$ ). The remaining SDS was removed by ion pair extraction (Henderson et al., 1979) and the ZP3 renatured by dialysis against 6 mol guanidine hydrochloride $1^{-1}$ (McCoy \& Wong, 1981). It was then dialysed at $4^{\circ} \mathrm{C}$ against $25 \mathrm{mmol}$ ammonium acetate $\mathrm{l}^{-1}$, and stored frozen at $-70^{\circ} \mathrm{C}$.

ZP3a-EBGD and ZP3 $-E B G D$. Purified ZP3 (approximately $40 \mathrm{mg}$ ) was first digested with Escherichia freundii endo- $\beta$-galactosidase at $37^{\circ} \mathrm{C}$ for $24 \mathrm{~h}$ in $100 \mathrm{mmol}$ ammonium acetate $\mathrm{l}^{-1}, \mathrm{pH} 5 \cdot 6$, containing $0 \cdot 1 \%$ toluene. Endo- $\beta$ galactosidase selectively hydrolyses terminal portions of polylactosamine-type oligosaccharides on ZP3 $\alpha$ and ZP3 $\beta$, resulting in shortened oligosaccharides with concomitant reduction in relative molecular mass and charge heterogeneity 
of each glycoprotein. The digest was then dissolved in $0 \cdot 1 \%$ trifluoroacetic acid followed by reverse phase high performance liquid chromatography using a $\mathrm{C} 4$ column eluted with an acetonitrile gradient. Fractions were analysed by SDS-polyacrylamide gel electrophoresis to determine the elution positions of ZP3a-EBGD and ZP3 $\beta$-EBGD.

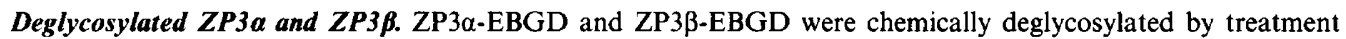
with a trifluoromethanesulfonic acid:anisole $(2: 1)$ preparation for $6 \mathrm{~h}$ at $4^{\circ} \mathrm{C}$. After neutralization with aqueous pyridine and extraction with diethyl ether, the deglycosylated samples were exhaustively dialysed against $50 \mathrm{mmol}$ ammonium acetate $1^{-1}\left(\mathrm{pH} \mathrm{5 \cdot 0)}\right.$ at $4^{\circ} \mathrm{C}$ to remove carbohydrate fragments. This material, referred to as ZP3 $\alpha$-DG and ZP3 $\beta$-DG, was then lyophilized and stored at $-20^{\circ} \mathrm{C}$.

Electrophoretic profiles were obtained of the various zona molecules used in this study (Fig. 1).

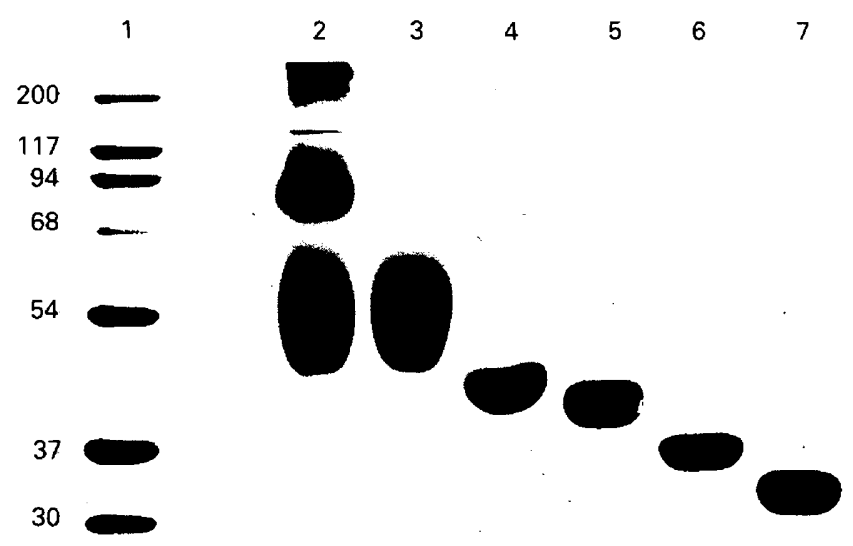

21

Fig. 1. SDS PAGE electrophoretic profiles of the porcine zona pellucida antigens. Lane 1: protein standards; Lane 2: SIZP; Lane 3: ZP3; Lane 4: ZP3 $\alpha$-EBGD; Lane 5: ZP3 $\beta$-EBGD; Lane 6: ZP3 $\alpha$-DG; Lane 7: ZP3 $\beta$-DG. Electrophoresis was performed under nonreducing conditions and proteins stained with Coomassie Brilliant Blue.

\section{Immunization}

Forty-eight female, sexually mature, Dutch-belted rabbits, 6 months of age, were assigned to one of the following groups: group I: SIZP $(n=6)$; group II: ZP3 $(n=6)$; group III: ZP3 $\alpha$-EBGD $(n=6)$; group IV: ZP3 $\beta$-EBGD $(n=6)$; group V: ZP3a-DG $(n=6)$; group VI; ZP3 $\beta$-DG $(n=6)$; group VII: Freund's complete adjuvant alone $(n=6)$; group VIII: $0 \cdot 15$ mol saline $1^{-1}(n=6)$. Groups I-VI were designated as treatment groups and groups VII and VIII as control groups.

Each animal in the treatment groups was injected with a total of $120 \mu \mathrm{g}$ of antigen as follows: half $(60 \mu \mathrm{g})$ of the total dose was divided equally in a series for three injections once a week. The remaining antigen $(60 \mu \mathrm{g})$ was administered as a single booster dose once peak antibody titres to ZP3 were obtained as determined by radioimmunoassay (Subramanian et al., 1981).

For injections, antigens were solubilized in $0.1 \mathrm{~mol}$ phosphate-buffered saline (pH 7.2) $1^{-1}$ (PBS) and emulsified immediately before use in an equal volume of Freund's complete adjuvant. Total volume per injection was $1.0 \mathrm{ml}$. Immunizations were performed using a multisite intradermal injection regimen. Freund's complete adjuvant was used for the first injection and Freund's incomplete adjuvant for all subsequent injections including the booster. Control groups were injected in a similar way with either equal volumes of Freund's adjuvant and PBS, or with saline alone using the same injection technique and schedule.

\section{Serum collection}

Blood was obtained from the marginal ear vein each week $(5 \mathrm{ml})$ starting 1 week after initial immunization and continuing until 1 month after administration of the booster. Blood was then obtained once a month for the 
remainder of the study. Serum was collected and stored at $-20^{\circ} \mathrm{C}$ until assayed for antibody titres and serum oestradiol levels.

\section{Radioimmunoassay}

Antibody response to the various zona subfractions was measured by a double antibody radioimmunoassay following procedures previously described for the zona system (Subramanian et al., 1981; Sacco et al., 1983). $\left[{ }^{125} \mathrm{l}\right]$-labelled ZP3 was used as tracer and all sera assayed for titre determination were diluted 1:1000 before use. Details of assay validation for sensitivity, precision, accuracy, specificity and other parameters have been described by Subramanian et al. (1981).

\section{Histology}

The effect of immunization with the various zona antigens on follicular development was monitored: two animals per group $(n=16)$ underwent laparotomy and unilateral oophorectomy every 6 weeks. Thus, two ovaries from different animals representative of each group were examined every 6 weeks over a period of 36 weeks. After removal, ovaries were weighed, fixed in formalin, embedded in paraffin and $4 \mu \mathrm{m}$ sections obtained. Sections were obtained at five different and nonadjacent levels through the ovary with the third level being at the approximate midpoint. Sections were stained with haematoxylin and eosin. Follicular development was evaluated by counting the number of primary, secondary and tertiary follicles observed at each level. Follicular stage was categorized as previously described (Erickson et al., 1986). Each animal underwent a repeat laparotomy for removal of the remaining ovary 18 weeks after the initial surgery. The second ovary was processed as described above.

\section{Statistical analysis}

Statistical analyses were conducted using the BMDP-PC 1990 Statistical Software Package (BMDP Statistical Software, Los Angeles, CA). The 7D program was used for conducting the analysis of variance (ANOVA) as well as for post-hoc comparison tests (Tukey Studentized Range and Student-Newman-Keuls). The $4 \mathrm{~V}$ program was used for conducting a mixed design repeated measures multivariate analysis of variance (MANOVA). Both among, and within, contrast effects were computed for the evaluation of time, treatment and level factors on ovarian histology. User-defined simple contrasts were conducted to compare the various treatment conditions with one another.

\section{Results}

\section{Antibody titres}

After the initial immunization series of three injections, and booster administration at 15 weeks, antibody titres rose rapidly and peaked at 18 weeks after initial immunization at the $50-70 \%$ binding level depending upon the particular immunogen injected (Fig. 2).

Titration profiles for all antigen groups were similar but antibody titres varied depending upon antigen used. A direct relationship was observed between immunogenicity and carbohydrate content of the immunogen. Fully glycosylated SIZP and ZP3 showed the highest binding $(71.9 \% \pm 1 \cdot 2 \%$ and $70.0 \% \pm 2.5 \%$, respectively) while ZP3 $\alpha-D G$ and ZP3 $\beta-D G$ showed the lowest $(56.4 \% \pm 4.0 \%$ and $53 \cdot 5 \% \pm 4.3 \%$, respectively) (mean \pm SEM). A significant decrease in binding $(P=<0.01)$ was noted for all groups between the peak binding observed at approximately 18 weeks and at 38 weeks after immunization, the point at which the study was terminated. No zona antibody activity was detected in animals in either of the control groups (groups VII and VIII) or in the pre-immunization control blood samples from all rabbits.

\section{Histology}

No statistical differences in follicular development were observed in ovaries obtained from rabbits in the saline or adjuvant control groups. Data from these control groups were therefore pooled for comparison with treatment groups.

In general, a direct correlation was found between degree of ovarian histopathology observed and carbohydrate content of the immunogen injected. Ovaries from SIZP-and ZP3-immunized 


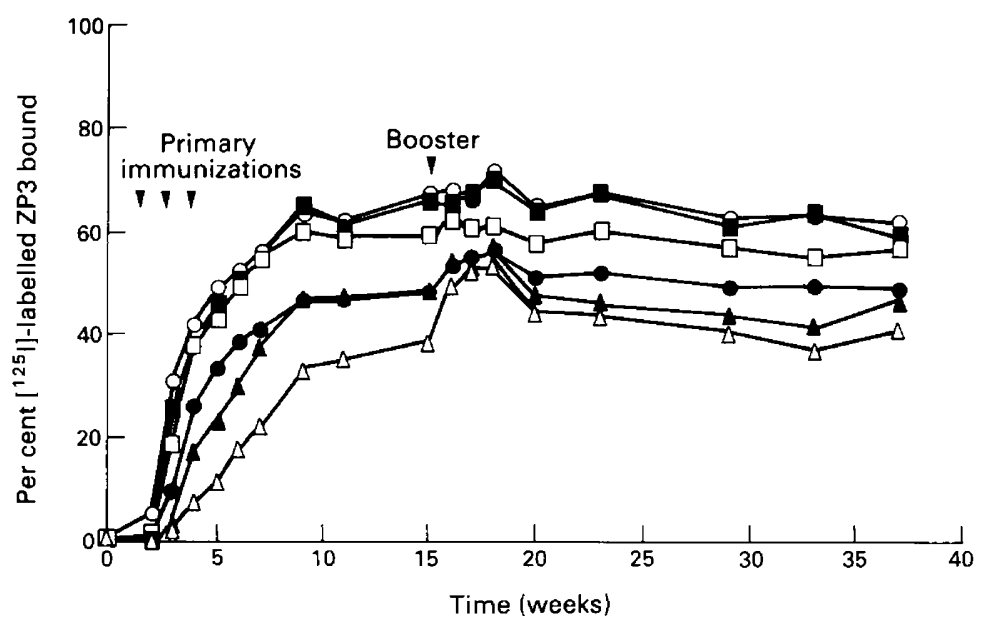

Fig. 2. Antibody titre response of the porcine zona pellucida antigens $(O)$ SIZP; ( $\square) Z P 3 ;(\square)$ ZP3 $\alpha$-EBGD; (๑) ZP3 $\beta$-EBGD; ( $\Delta$ ) ZP3 $\alpha$-DG; $(\triangle)$ ZP3 $\beta$-DG as measured using a double antibody radioimmunoassay. Titres are expressed as per cent binding of $\left[{ }^{125} \mathrm{I}\right]$-labelled $\mathrm{ZP} 3$ using a 1:1000 antiserum dilution.

rabbits showed the earliest and greatest follicular growth disruption compared with the controls. In these two groups, disturbances in follicular development were observed as early as 6 and 12 weeks after initial immunization with SIZP and ZP3, respectively (Fig. 3a,b). SIZP- and ZP3immunized animals showed significantly fewer $(P<0.01)$ primary, secondary and tertiary follicles compared with controls (Fig. 4) and continued to show this marked disruption of follicular development throughout the course of the study (Fig. 3c,d). Oocytes, if still present, showed cytoplasmic disruption and poorly visualized nuclei. A time effect was noted histologically, but such an effect could not be shown statistically owing to the number of animals in each treatment group.

Ovaries from $Z P 3 \beta$-EBGD-immunized rabbits showed an obvious reduction in all stages of follicle development (Fig. 5b) first observed at 24 weeks after immunization (Fig. 6a). Ovaries from rabbits immunized with ZP3 $\beta$-DG showed a significant decrease in primary follicles, apparent initially at approximately 18 weeks after immunization. Secondary and tertiary follicular development in this group did not differ significantly from the controls over the 36 weeks after immunization (Fig. 7b). In addition, oocytes and their surrounding zona pellucida appeared intact with no discernible disruptions (Fig. 6d).

ZP3 $\alpha$-EBGD- and ZP3 $\alpha$-DG-immunized rabbits, in contrast, showed normal follicular development (Fig. 6b,c) and no statistically significant reduction in tertiary, secondary or primary follicular development compared with controls for the duration of the study (Figs 5a and 7a). Furthermore, repeated histological evaluation failed to reveal any evidence of cortical thinning, perifollicular fibrosis, stromal cell hyperplasia, leucocytic infiltration or zona pellucida disruption for both ZP3 $\alpha$-EBGD- and ZP3 $\alpha$-DG-, as well as for ZP3 $\beta$-DG-immunized animals (Table 1).

\section{Discussion}

Porcine zona-based immunocontraceptive studies in vitro and in vivo have demonstrated clearly the contraceptive efficacy and promise of this approach towards development of a prefertilization contraceptive vaccine. However, to date, a major drawback has been the observed disruption of normal ovarian cyclicity and folliculogenesis in some species after immunization with porcine zona material. Disturbances ranged from being totally absent to being mild to severe depending upon 

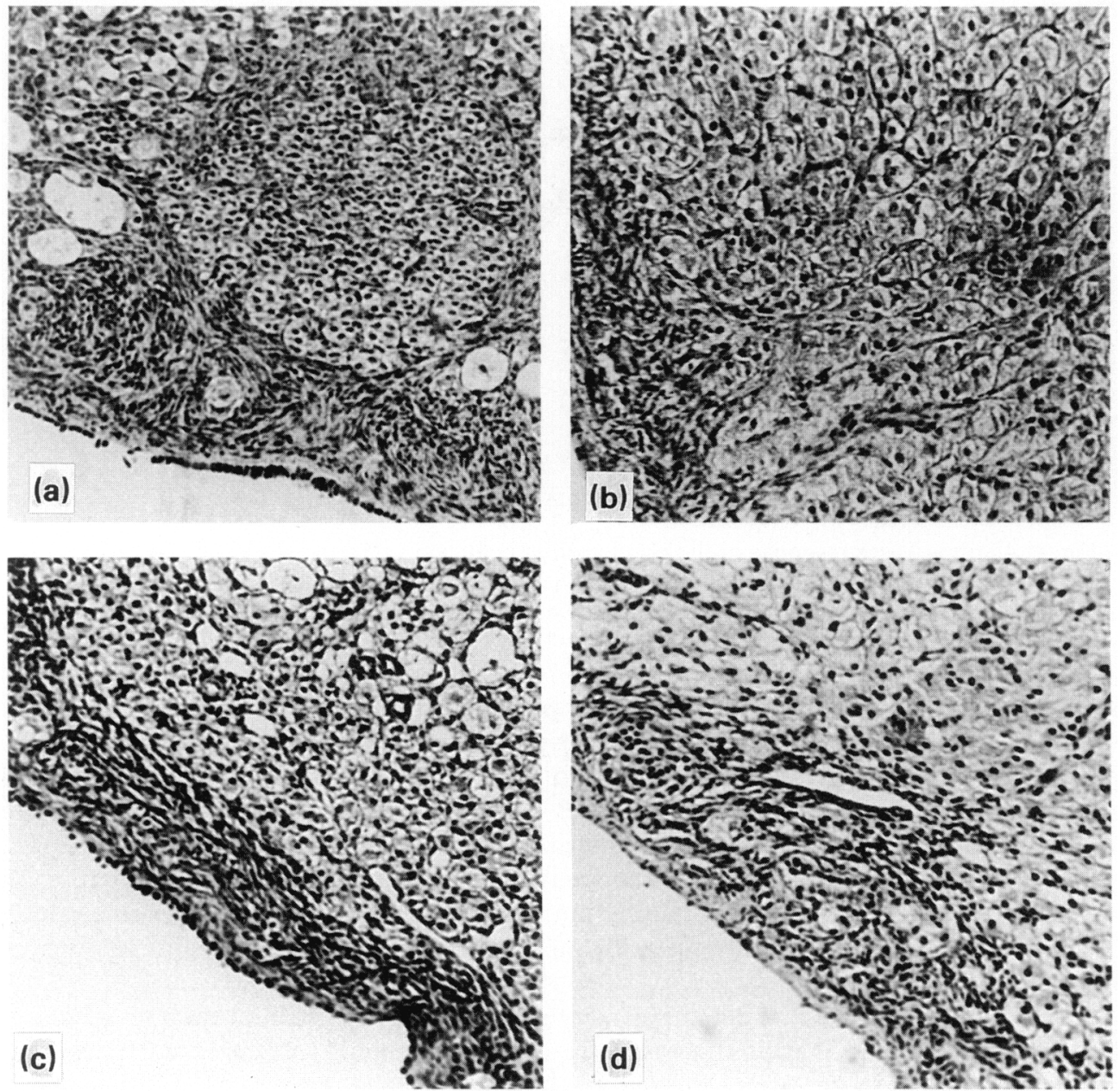

Fig. 3. Representative rabbit ovarian cross-sections at 6,12 , and 36 weeks after initial immunization: (a) SIZP-immunized animal at 6 weeks; (b) ZP3-immunized animal at 12 weeks; (c) SIZP-immunized animal at 36 weeks; (d) ZP3-immunized animal at 36 weeks. The marked disruption of primary, secondary and tertiary follicular development is evident. $\times 275$.

species immunized and porcine zona immunogen used. Although the precise mechanism of this disruption is unclear, these data do emphasize that antibodies to zona pellucida can inhibit fertilization effectively at either of two levels, sperm-egg interaction, folliculogenesis or both. Current efforts in zona-based immunocontraception are now focused on identifying or developing zona immunogens that elicit antibodies with contraceptive activity that disrupts only sperm-egg interaction.

In an attempt to identify such a zona immunogen, we compared ovarian histological findings from rabbits immunized with a number of glycosylated and deglycosylated porcine zona components. Rabbits were chosen since they appear to be particularly sensitive to zona-antibody-induced disruptions of normal ovarian cyclicity and folliculogenesis (Skinner et al., 1984; Sehgal et al., 1989). A zona immunogen that does not produce ovarian histopathology in rabbits would be an excellent prospective target antigen for additional immunocontraceptive studies in more appropriate species such as nonhuman primates. This study is also the first in which such a panel of zona immunogens was examined for this purpose in a single species. 

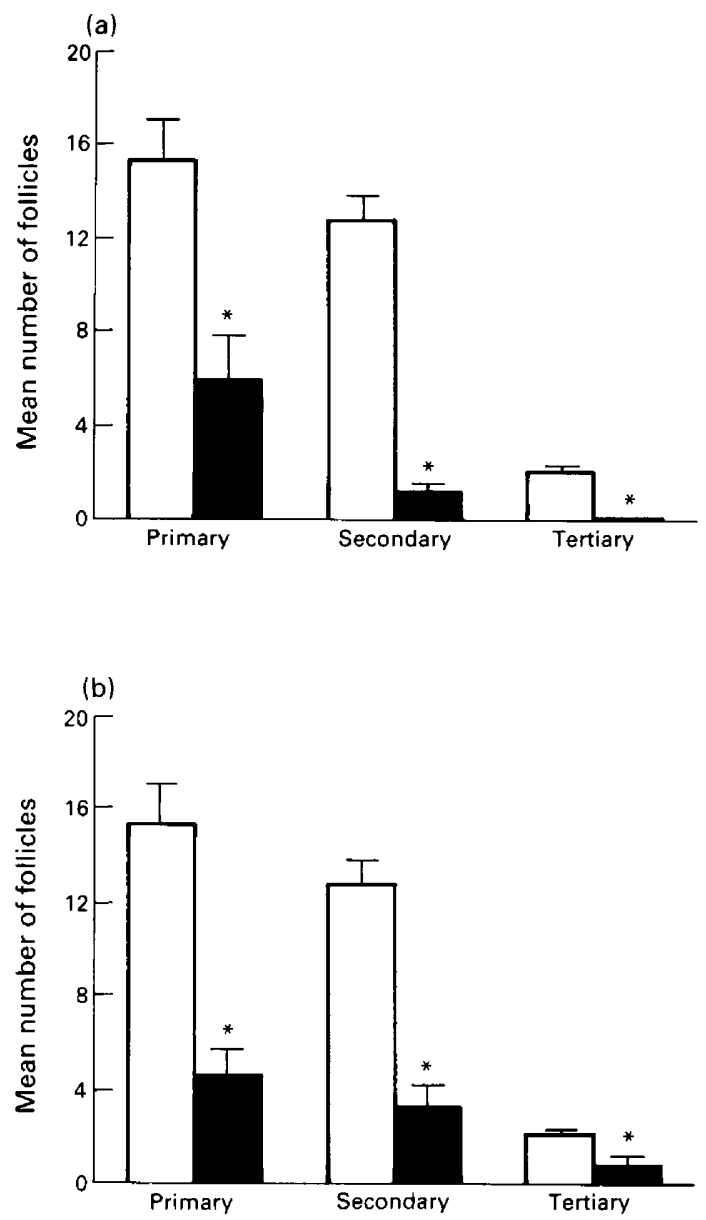

Fig. 4. Follicular development in (a) SIZP- and (b) ZP3-immunized animals ( $\boldsymbol{\square}$ ) versus controls $(\square)$. A significant reduction in development of primary, secondary and tertiary follicles was observed for both groups. ${ }^{*} P<0 \cdot 01$, MANOVA. Significance values represent overall effect for each treatment group. Each value for follicular number represents the group mean from pooled data from six animals over the duration of the study.

Immunization with the glycosylated zona components, SIZP and ZP3, resulted in severe disruptions to normal ovarian histology which were detected 6 to 12 weeks after immunization with SIZP and ZP3, respectively. Ovaries from these animals were characterized by drastic reductions, or alteration, or by both, of all follicular stages. These findings are thus similar to other investigations which used total zona proteins (i.e. SIZP) for immunization of either rabbits (Skinner $e t$ al., 1984; Sehgal et al., 1989) or other species (Gulyas et al., 1983; Mahi-Brown et al., 1988). The ovarian histological disruptions observed in this study after immunization of rabbits with ZP3 were also similar to results obtained in species such as dogs (Mahi-Brown et al., 1988), squirrel monkeys (Sacco et al., 1987, 1990, 1991), bonnet monkeys (Upadhyay et al., 1989) and baboons (Dunbar et al., 1989). Collectively, these data indicate that SIZP and ZP3, in their native glycosylated state, probably would not serve as appropriate contraceptive vaccine target antigens for continued investigation.

Histological findings from use of the partially deglycosylated ZP3 $\alpha$-EBGD were much more encouraging since no adverse effects on ovarian histology were observed throughout the 36 weeks 

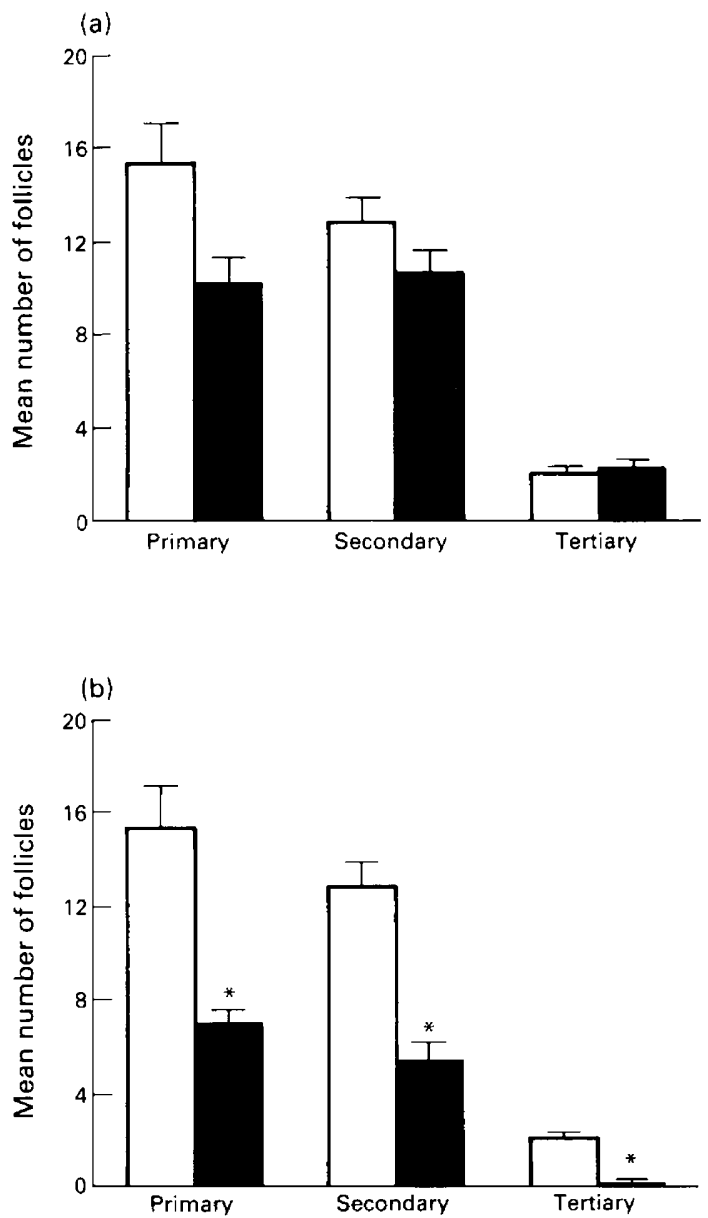

Fig. 5. Development of follicles in (a) ZP3 $\alpha$-EBGD and (b) ZP3 $\beta$-EBGD-immunized animals (a) versus controls $(\square)$. ZP3 $\alpha$-EBGD showed no overall significant reduction in follicular development compared to controls $(P>0.05$, MANOvA), whereas ZP3 $\beta$-EBGD showed a significant reduction in primary, secondary and tertiary follicle number compared to controls. $* P<0.01$, manova. Values represent group mean from pooled data for six animals over the duration of the study.

of the investigation. Use of the partially deglycosylated ZP3 $\beta$-EBGD immunogen, however, did produce a marked decrease in all types of follicles by 24 weeks after immunization.

Similar findings were obtained from experiments using ZP3 $\alpha$-DG and ZP3 $\beta$-DG. No adverse effects on ovarian histology were noted when $Z P 3 \alpha$-DG was used as immunogen but immunization with ZP3 $\beta-D G$ did result in a statistically significant decrease in primary follicles. Collectively, experiments using both partially deglycosylated zona components and deglycosylated components designate $\mathrm{ZP} 3 \alpha$ as the most promising candidate antigen for future investigation. The ZP3 $\alpha$ component has recently been shown to be functionally significant in the fertilization process since it possesses sperm receptor activity (Sacco et al., 1989a).

These histological findings concur with a recent endocrinological study in rabbits, which used the same zona immunogens (Keenan et al., 1991). In this study, animals immunized with SIZP, ZP3 and ZP3 $\beta$-EBGD showed significant perturbation of luteinizing hormone, follicle-stimulating hormone and progesterone levels, whereas animals immunized with ZP3 $\alpha$-EBGD, ZP3 $\alpha$-DG and 

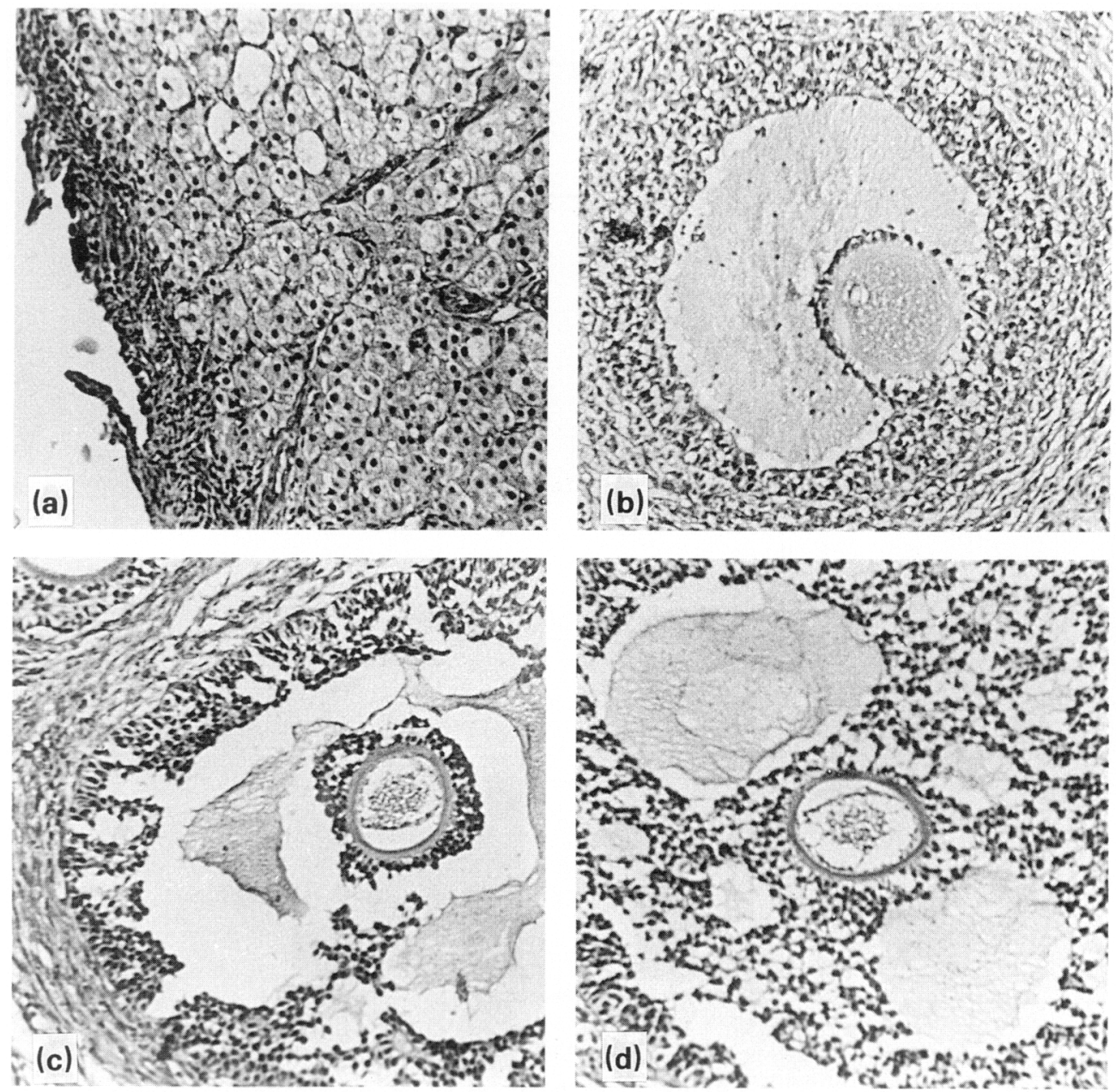

Fig. 6. Representative rabbit ovarian cross-sections at 24 weeks and 36 weeks: (a) ZP3ßEBGD-immunized animal at 24 weeks; (b) ZP3 $\alpha$-EBGD-immunized animal at 36 weeks; (c) ZP3 $\alpha$-DG-immunized animal at 36 weeks; (d) ZP3 $\beta$-DG-immunized animal at 36 weeks. Absence of follicular development is evident in ZP3 $\beta$-EBGD immunized animal. Normal tertiary follicles are noted in the remaining groups.

ZP3 $\beta$-DG displayed no significant disruptions in normal hormone profiles. Coupled with our histological findings, these data indicate that immunization with ZP3 $\alpha$-EBGD and ZP3 $\alpha$-DG does not disrupt normal ovarian function in the rabbit, in spite of the presence of high-titred zona antisera directed against these components. These findings encourage the continued investigation of partially deglycosylated and deglycosylated zona components for immunocontraceptive purposes. They are also of particular relevance to those studies directed towards engineered contraceptive vaccines based upon synthetic or recombinant peptide molecules.

Whereas carbohydrate has been demonstrated to play a significant role in the immunogenicity and antigenicity of the porcine zona ZP3 molecule (Sacco et al., 1986), high-titred zona antisera that possess contraceptive activity can be produced against enzymatically and chemically deglycosylated zona components (Henderson et al., 1987a, b; Sacco et al., 1989a; Aitken et al., 1990). Contraceptive zona antibodies are also elicited when synthetic zona peptides (Millar et al., 1989; Sacco et al., 1989b) are used as immunogens. These data suggest that certain deglycosylated 

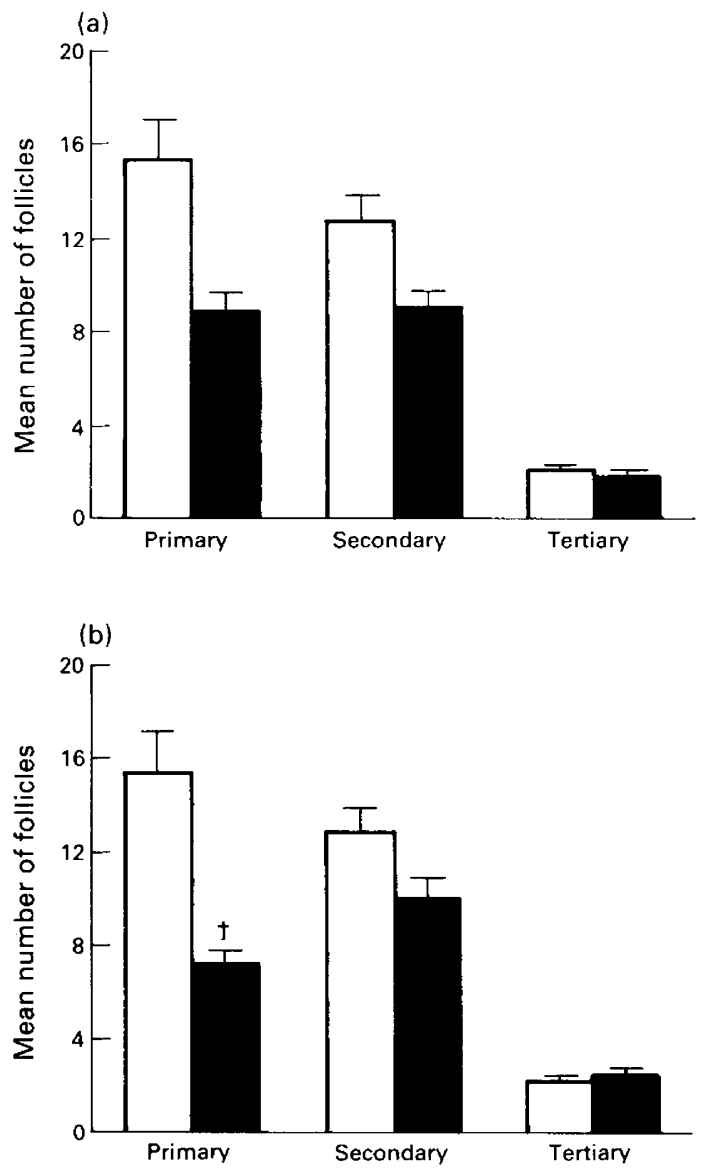

Fig. 7. Development of follicles in (a) ZP3 $\alpha$-DG and (b) ZP3 $\beta$-DG-immunized animals. No significant reduction in follicle number was noted for ZP3 $\alpha-D G$ versus controls $(P>0.05$, MANOVA), while ZP3 $\beta$-DG revealed a reduction in primary follicles compared only with controls. ${ }^{*} P<0.05$, MANOVA. Values represent group mean from pooled data for six animals over the duration of study.

porcine zona components can elicit high-titred contraceptive antibodies that produce no adverse effects on the ovary.

Current findings indicate that, whereas significantly high titres $(>53.5 \%$ binding by radioimmunoassay in this study) can be produced against deglycosylated zona immunogens, such titres typically are lower than those produced against the corresponding glycosylated form. It is unclear whether the lack of histopathological effects on ovaries observed in this study with use of deglycosylated zona components can be attributed to these lower titres or to qualitative differences in the antibodies themselves which are developed against the glycosylated or deglycosylated components. Data from the present investigation support the latter suggestion. For example, quantitatively similar titres were obtained using ZP3 $\alpha$-EBGD and ZP3 $\beta$-EBGD. Yet, immunization with ZP3 $\alpha$-EBGD had no effect on ovarian histology while immunization with ZP3 $\beta$-EBGD did result in significant reductions of primary, secondary and tertiary follicles. These results suggest that the qualitative nature of the antibodies induced after immunization with such zona components may be more significant than the absolute titre obtained. Obviously, additional studies must be performed to clarify this issue. 
Table 1. Histopathological effects on rabbit ovarian follicular development after injection with various glycosylated and deglycosylated porcine zona pellucida immunogens

\begin{tabular}{|c|c|c|c|c|c|}
\hline \multirow[b]{2}{*}{ Immunogen } & \multirow{2}{*}{$\begin{array}{c}\text { Percentage } \\
\text { deglycosylated }\end{array}$} & \multicolumn{3}{|c|}{ Follicular stage } & \multirow{2}{*}{$\begin{array}{l}\text { First appearance } \\
\text { after immunization }\end{array}$} \\
\hline & & $P$ & $\mathrm{~S}$ & $\mathrm{~T}$ & \\
\hline SIZP & 0 & $*$ & $*$ & * & 6 weeks \\
\hline $\mathrm{ZP} 3$ & 0 & $*$ & * & * & 12 weeks \\
\hline $\mathrm{ZP} 3 \alpha-E B G D$ & $\approx 30$ & - & - & - & NA \\
\hline ZP3ß-EBGD & $\approx 30$ & $*$ & * & * & 24 weeks \\
\hline$Z P 3 \alpha-D G$ & $\approx 92$ & - & - & - & NA \\
\hline ZP3 $\beta-D G$ & $\approx 92$ & $\dagger$ & - & - & 18 weeks \\
\hline None & NA & - & - & - & NA \\
\hline
\end{tabular}

${ }^{a}$ Gas chromatography was used to determine sugar content as detailed by Yurewicz et al. (1987) and Sacco et al. (1986).

${ }^{b}$ Time after immunization when histopathological effect first noted.

*Significantly different from controls (MANOVA; $P<0.01$ ).

$-:$ no significant difference from controls (MANOVA; $P>0.05$ ).

+Significantly different from controls (MANOVA; $P<0.05$ ).

NA: not applicable; P: primary follicle; S: secondary follicle; T: tertiary follicle.

In summary, immunization of rabbits with ZP3 $\alpha$-EBGD and ZP3 $\alpha$-DG elicits high-titred zona antisera that have no adverse effects on normal ovarian histology. Earlier findings (Keenan et al., 1991) have indicated that immunization with these components also does not disrupt ovarian cyclicity and endocrine profiles. ZP $3 \alpha-E B G D$ and ZP $3 \alpha-D G$ are therefore primary immunocontraceptive target antigens for future investigation.

We would like to thank Ida Thompson for her excellent secretarial assistance. This study was supported in part by NIH Grant No. HD 23787.

\section{References}

Aitken, R.J., Paterson, M., Braude, P. \& Thillaikoothan, P. (1990) Evaluation of glycosylated and deglycosylated porcine zona antigens for contraceptive efficacy in vivo and in vitro. In Gamete Interaction: Prospects for Immunocontraception, pp. 293-311. Eds N. J. Alexander, D. Griffin, J. M. Spieler \& G. M. H. Waites. Wiley-Liss, New York.

Bleil, J.D. \& Wassarman, P.M. (1983) Sperm-egg interactions in the mouse: sequence of events and induction of the acrosome reaction by a zona pellucida glycoprotein. Developmental Biology 95, 317-324.

Braden, A.W.H., Austin, C.R. \& David, H.A. (1954) The reaction of the zona pellucida to sperm penetration. Australian Journal of Biology 7, 391-409.

Cherr, G.N., Lambert, H., Meizel, S. \& Katz, D.F. (1986) In-vitro studies of the golden hamster sperm acrosome reaction: completion on the zona pellucida and induction by homologous soluble zonae pellucidae. Developmental Biology 114, 119-131.

Dunbar, B.S. (1983) Antibodies to zona pellucida antigens and their role in fertility. In Immunology of Reproduction, pp. 507-534. Eds T. G. Wegmann, T. J. Gill \& C. D. Cumming. Oxford University Press, New York.

Dunbar, B.S., Liu, C. \& Sammons, D.W. (1981) Identification of the three major proteins of porcine and rabbit zonae peliucidae by high resolution two-dimensional gel electrophoresis: comparison with serum, follicular fluid and ovarian cell proteins. Biology of Reproduction 24, 1111-1124.

Dunbar, B.S., Lo, C., Powell, J. \& Stevens, V.C. (1989) Use of synthetic peptide adjuvant for immunization of baboons with denatured and deglycosylated pig zona pellucida glycoproteins. Fertility and Sterility 52, 311-318.

Erickson, G.F. (1986) An analysis of follicle development and ovum maturation. In Seminars in Reproductive Endocrinology, Vol. 4, pp. 233-254. Ed. D. F. Archer. Thieme, Inc, NY.

Gulyas, B.J., Gwatkin, R.B.L. \& Yuan, L.C. (1983) Active immunization of cynomolgus monkeys (Macaca fascicularis) with porcine zonae pellucidae. Gamete Research 4, 299-307.

Hanada, A. \& Chang, M.C. (1972) Penetration of zonafree eggs by spermatozoa of different species. Biology of Reproduction 6, 300-309.

Hedrick, J.L. \& Wardrip, N.J. (1987) On the macromolecular composition of the zona pellucida from porcine oocytes. Developmental Biology 121, 478-488.

Henderson, C.J., Braude, P. \& Aitken, R.J. (1987a) Polyclonal antibodies to a $32-\mathrm{kDa}$ deglycosylated polypeptide from porcine zonae pellucidae will 
prevent human gamete interaction in vitro. Gamete Research 18, 251-265.

Henderson, C.J., Hulme, M.J. \& Aitken, R.J. (1987b) Analysis of the biological properties of antibodies raised against intact and deglycosylated porcine zonae pellucidae. Gamete Research 16, 323-341

Henderson, C.J., Hulme, M.J. \& Aitken, R.J. (1988) Contraceptive potential of antibodies to the zona pellucida. Journal of Reproduction and Fertility 83, $325-343$.

Henderson, L.E., Oroszlan, S. \& Konigsberg, W. (1979) A micromethod for complete removal of dodecyl sulfate from proteins by ion-pair extraction. Analytical Biochemistry 93, 153-157.

Keenan, J.A., Sacco, A.G., Subramanian, M.G., Kruger, M., Yurewicz, E.C. \& Moghissi, K.S. (1991) Endocrine response in rabbits immunized with native versus deglycosylated porcine zona pellucida antigens. Biology of Reproduction 44, 150-156.

Koyama, K., Hasegawa, A., Tsuji, Y. \& Isojima, S. (1985) Production and characterization of monoclonal antibodies to cross-reactive antigens of human and porcine zonae pellucidae. Journal of Reproductive Immunology 7, 187-198.

McCoy, L.F., Jr \& Wong, K.P. (1981) Renaturation of bovine erythrocyte carbonic anhydrase $\mathrm{B}$ denatured by acid, heat and detergent. Biochemistry, NY 20, 3062-3067.

Mahi-Brown, C.A., Yanagimachi, R., Hofiman, J.C. \& Huang, T.T.F. (1985) Fertility control in the bitch by active immunization with porcine zona pellucida: use of different adjuvants and patterns of estradiol and progesterone levels in estrous cycles. Biology of Reproduction 32, 761-772.

Mahi-Brown, C.A., Yanagimachi, R., Nelson, M.L., Yanagimachi, H. \& Palrimbo, N. (1988) Ovarian histopathology of bitches immunized with porcine zonae pellucidae. American Journal of Reproductive Immunology and Microbiology 18, 94-103.

Maresh, G.A. \& Dunbar, B.S. (1987) Antigenic comparison of five species of mammalian zonae pellucidae. Journal of Experimental Zoology 244, 299-307.

Millar, S.E., Chamow, S.M., Baur, A.W., Oliver, C., Robey, F. \& Dean, J. (1989) Vaccination with a synthetic zona pellucida peptide produces long-term contraception in female mice. Science 246, 935--938.

O'Rand, M.G. (1988) Sperm-egg recognition and barriers to interspecies fertilization. Gamete Research 19, 315-328.

Sacco, A.G. (1977) Antigenic cross-reactivity between human and pig zona pellucida. Biology of Reproduction 16, 164-173.

Sacco, A.G. (1981) Immunocontraception: consideration of the zona pellucida as a target antigen. In Obstetrics and Gynecology Annual, Vol. 10, pp. 1-26. Ed. R. M. Wynn. Appleton-Century-Crofts, New York.

Sacco, A.G. (1987) The zona pellucida: current status as a candidate antigen for contraceptive vaccine development. American Journal of Reproductive Immunology and Microbiology 15, 122-130.

Sacco, A.G., Yurewicz, E.C., Subramanian, M.G. \& DeMayo, F.J. (1981) Zona pellucida composition: species cross-reactivity and contraceptive potential of antiserum to a purified pig zona antigen (PPZA). Biology of Reproduction 25, 997-1008.
Sacco, A.G., Subramanian, M.G., Yurewicz, E.C., DeMayo, F.J. \& Dukelow, W.R. (1983) Heteroimmunization of squirrel monkeys with a purified porcine zona antigen (PPZA): immune response and biologic activity of antiserum. Fertility and Sterility 39, 350-358.

Sacco, A.G., Yurewicz, E.C. \& Subramanian, M.G. (1986) Carbohydrate influences the immunogenic and antigenic characteristics of the ZP3 macromolecule $\left(M_{\mathrm{r}}=55000\right)$ of the pig zona pellucida. Journal of Reproduction and Fertility 76, 575-586.

Sacco, A.G., Pierce, D.L., Subramanian, M.G., Yurewicz, E.C. \& Dukelow, W.R. (1987) Ovaries remain functional in squirrel monkeys (Saimiri sciureus) immunized with porcine zona pellucida $55 \mathrm{~K}$ macromolecule. Biology of Reproduction 36, 481-490.

Sacco, A.G., Yurewicz, E.C., Subramanian, M.G. \& Matzat, P.D. (1989a) Porcine zona pellucida: association of sperm receptor activity with the $\alpha$ glycoprotein (ZP3- $\alpha$ ) of the $M_{\mathrm{r}}=55000$ family (ZP3). Biology of Reproduction 41, 523-532.

Sacco, A.G., Yurewicz, E.C. \& Subramanian, M.G. (I989b) Contraceptive activity of antiserum to a synthetic peptide conjugate of porcine zona pellucida glycoprotein ZP3- $\alpha$. Scientific Program and Abstracts Society for Gynecologic Investigation, 36th Annual Meeting p. 329. Abstract 796.

Sacco, A.G., Yurewicz, E.C., Subramanian, M.G. \& Ye, L. (1990) Analysis of the porcine zona pellucida $M_{\mathrm{r}}=55000$ antigen for contraceptive use. In Reproductive Immunology, 1989. Proceedings of the Fourth International Congress of Reproductive Immunology, pp. 117-125. Eds L. Mettler \& W. D. Billington. Elsevier, Amsterdam.

Sacco, A.G., Yurewicz, E.C., Subramanian, M.G., Ye, L. \& Dukelow, W.R. (1991) Immunologic response and ovarian histology of squirrel monkeys (Saimiri sciureus) immunized with porcine zona pellucida ZP3 $\left(M_{\mathrm{r}}=55000\right)$ macromolecules. American Journal of Primatology, 24, 15-28.

Sehgal, S., Gupta, S.K. \& Bhatnagar, P. (1989) Longterm effects of immunization with porcine zona pellucida on rabbit ovaries. Pathology 21, 105-110.

Skinner, S.M., Mills, T., Kirchick, H.J. \& Dunbar, B.S. (1984) Immunization with zona pellucida proteins results in abnormal ovarian follicular differentiation and inhibition of gonadotropin-induced steroid secretion. Endocrinology 115, 2418-2432.

Subramanian, M.G., Sacco, A.G. \& Yurewicz, E.C. (1981) Specific radioimmunoassay for the detection of purified porcine zona pellucida antigen (PPZA). Biology of Reproduction 24, 933-943.

Trounson, A.O., Shivers, C.A., McMaster, R. \& Lopata, A. (1980) Inhibition of sperm binding and fertilization of human ova by antibody to porcine zona pellucida and human sera. Archives of Andrology 4, 29-36.

Upadhyay, S.N., Thillaikoothan, P., Bamezai, A., Jayaraman, S. \& Talwar, G.P. (1989) Role of adjuvants in inhibitory infuence of immunization with porcine zona pellucida antigen (ZP3) on ovarian folliculogenesis in bonnet monkeys: a morphological study. Biology of Reproduction 41, 665-673.

Wassarman, P. M. (1988) Zona pellucida glycoproteins. Annual Reviews of Biochemistry 57, 415-442. 
Yurewicz, E.C., Sacco, A.G. \& Subramanian, M.G. (1983) Isolation and preliminary characterization of a purified pig zona antigen (PPZA) from porcine oocytes. Biology of Reproduction 29, 511-523.

Yurewicz, E.C., Sacco, A.G. \& Subramanian, M.G. (1986) Pathways to immunocontraception: biochemical and immunobiological properties of the glycoprotein antigens of the porcine zona pellucida.
In Molecular and Cellular Biology of Fertilization, pp. 407-427. Ed. J. L. Hedrick. Plenum Press, New York.

Yurewicz, E.C., Sacco, A.G. \& Subramanian, M.G. (1987) Structural characterization of the $M_{\mathrm{r}}=55000$ antigen (ZP3) of porcine oocyte zona pellucida. Journal of Biological Chemistry 262, 564-571.

Received 3 April 1991 